\title{
FEATURES OF PROVIDING THE VALUE OF PROJECTS FOR STAKEHOLDERS UNDER CONDITIONS OF UKRAINIAN BUSINESS
}

\author{
Anastasiia LIEZINA ${ }^{1}$ \\ Kyiv National Economic University named after Vadym Hetman, Ukraine
}

\begin{abstract}
The purpose of the work is to determine the value characteristics for the stakeholders of the project, identify existing types of projects in the field of providing electricity services, and describe the features of providing value in the Ukrainian business environment. The system analysis method and analytical method allowed analysing the development of project management from the point of introduction and use of "value" category of the project in practice and considering the features of providing value characteristics for the main stakeholders of the project. Methodology. The analysis of the project management system is based on providing value expectations for the project stakeholders in theory and in practice. The development of the electricity supply in the country is of great importance in the economic development of the country during the crisis stages. For the analysis, 3 enterprises were selected, carrying out their economic activities in this area on the territory of the Kyiv region. In order to determine the specifics of providing value to project stakeholders at all phases of the life cycle of the project, the main types of projects were identified and their percentage was analysed among the implemented projects at enterprises between 2009 and 2017. The definition of the project product for this field of activity is presented and the main stakeholders of the project are described. The analysis of project implementation provides for the existence of four phases of the life cycle, with a partial provision of value on each of them for interested parties. This indicates that entrepreneurs are not consciously seeking to improve their management skills in order to increase the efficiency of project implementation. Relevance/originality. Analytical data provide further development of this science in the field of application of value characteristics in the analysis of the effectiveness of projects. In the future, the system analysis of project management in practice makes it possible to assess the degree of the use of scientific developments and fill gaps.
\end{abstract}

Key words: project management, value, stakeholders, project product, project life cycle phases.

JEL Classification: D22, M11, 013

\section{1. Введение}

На протяжении последних мет практика управмения проектами набирает большей попумярности в украинском бизнесе. При этом основных критериев оценки успешности проектов неАостаточно ААя определения и обеспечения всех возможных результатов от проекта. ОАним из направлений развития Аанной науки является внеАрение и использование категории ценность проекта. На практике возможность обеспечивать ценностные ожидания Амя заинтересованных сторон явцяется оАним из процессов на пути к усовершенствованию и повышению эффективности методов управления проектами. Амя определения существующей практики в управлении ценностью проекта были выбраны отечественные преАприятия, которые осуществляют свою хозяйственную деятельность в рамках реализации проек- тов по преАоставлению услуг в сфере электроснабжения. Аанная отрасль была выбрана как стратегически важная с точки зрения развития экономики госуАарства. Кроме того, опираясь на нормативно-правовую базу Украины, а именно Закон Украины «О эмектроэнергетике», ГСН В.2.5-27-2006, ГСН В 2.2-15, ГСТУ Б В.2.5-38:2008 и Правила устройства эмектроустановок, мюбое новое подкцючение, реконструкция и переоснащение электротехнического оборудования может быть выполнено только при условии разработки, согласования и реализации проекта по выбранному виду деятельности. Соответственно можем утвержАать, что применение проектного менеАжмента в Аанной отрасли предоставления ускуг повысит эффективность реализованных проектов с точки зрения обеспечения ценности Аля всех заинтересованных сторон проекта.

Corresponding author:

${ }^{1}$ Department of Business Strategy, Kyiv National Economic University named after Vadym Hetman.

E-mail: lezya16@meta.ua 


\section{2. Составмяющие ценности проекта}

Развитие и становление категории ценность проекта обусловлено разнообразием подходов к опреАелению и, соответственно, к применению термина. Среди отечественных и зарубежных ученых слеАует обратить внимание на высказывания В.А. Рача, А.П. Батенко, С.А. Бушуева, С. Охара, Рассела А. Арчибальда. Все они определяют разные составцяющие ценности проекта. К примеру, С. А. Бушуев акцентирует внимание на выгодах, полученных от реализации проекта всеми заинтересованными сторонами и определяет ценность, как комплексный показатель (Bushuev, 2010). B. А. Рач отмечает ценность как уникацьные способности продукта проекта обеспечить Аостижение миссии в социально - экономической системе (Rach, 2010). Нам импонирует позиция Охара С., который определяет ценность проекта, как обеспечение конкретных ценностей конкретным заинтересованным сторонам проекта (Ohara, 2001). Поэтому мы считаем, что ценность проекта Аолжна содержать в себе слеАующие составмяющие:

- соответствие полученных характеристик продукта проекта запланированным и ожидаемым, то есть ценность созАанного проАукта Аостаточно УАовлетворяет потребности всех стейкхолАеров;

- соответствие продукта проекта стратегическим цемям и задачам компании, то есть способность преАоставить компании большую конкурентоспособность;

- соответствие выполнения проекта установленным критериям «железного треугольника», то есть вовремя, в пределах согласованного бюАжета и объемов наАлежащего качества;
- аккумумяция опыта участников проекта и формирование обновменной базы знаний, что приводит к совершенствованию методов и инструментария проектного управления.

Таким образом можем утвержаать, что ценность проекта созАается в процессе управления проектом и в процессе создания продукта проекта и имеет соответствующие индивидуальные и общие характеристики (рис. 1). Хотим акцентировать внимание на том, что Аля Аанной сферы преАоставления услуг продуктом проекта явцяется монтаж электроустановки, преАназначенной Аля потребления/трансформации/распреАеления электрической энергии жемаемого напряжения (220/380/10000/35000 В и выше) и заявменной мощности (от 1 кВт и выше) переменного тока частотой 50-60 Гц, выполненный в соответствии с нормативными требованиями Украины (ГСН В.2.5-27-2006, ГСН В 2.2-15, ГСТУ Б В.2.5-38:2008 и Правика устройства эмектроустановок).

\section{3. Ценностные ожиАания стейкхомАеров проекта}

Основываясь на теории заинтересованных сторон ЭАварда Р. Фримена (Freeman, 1984) и учитывая практику реализации проектов, их стейкхолдерами явмяются потребитель, заказчик, куратор, менеАжер проекта, чиены проектной команды, поставщики и окружение. Определим этих стейкхолдеров и их ценностные ожидания в рассматриваемой сфере ускуг.

1. Потребитель и заказчик - это чаще всего одно физическое/юридическое мицо, которое имеет жела-



Рис. 1. Составмяющие ценности проекта 
ние удовлетворить свои потребности посреАством использования электрической энергии. Аля него ценностью от реализации проекта явмяется получение своевременно и надлежащего качества продукта проекта, то есть установку безопасного эмектрического устройства соответствующей мощности, которая обеспечит ему постоянное использование электрической энергии, а также возможность получать финансовые поступления от всего сопутствующего оборудования (опор низко и высоковольтных, комплектных трансформаторных подстанций и Аругих зАаний и сооружений) посреАством преАоставления ускуг Аальнейшего пользования или отчуждения части имеющейся мощности Аругим стейкхолдерам.

2. Куратором явмяется Аиректор преАприятия или уполномоченное им мицо, которое предоставляет необходимые услуги в данной отрасли. Ценностные аспекты реализации проекта Амя него проявцяются в Авух направлениях: обеспечение индивидуальных и комлективных ожиданий. А именно, к первым можно отнести становцение Аеловой репутации, усовершенствование мидерских качеств, накопление опыта руководителя; ко вторым относятся расширение поля деятельности преАприятия, преимущества переА конкурентами, развитие технологий, финансовая стабильность и преумножение активов преАприятия.

3. МенеАжер проекта - это главный инженер преАприятия, который имеет соответствующее образование, группу Аопуска по эмектробезопасности и опыт работы в Аанной сфере. Его ценностные ожидания направлены на подАержание Аеловой репутации, получение финансовых вознаграждений в виде премий, повышение квамификации и накопление новых знаний, а также созАание баланса интересов межАу всеми участниками команды, что в Аальнейшем гарантирует создание ценности Аһя них.

4. Членами проектной команды явАяются преАставители преАприятия мибо приглашенные мица из Аругих организаций, которые непосредственно задействованы в реализации проекта. К этим стейкхолдерам относятся: инженер - проектант, инженер - сметчик, бухгалтер, исполнитель работ, электромонтеры, водители и эксперты. Аля них ценностными ожиданиями можно считать получение нового опыта работы в своей и смежных профессионацьных областях, обеспечение стабильного финансового Аохода, повышение квацификации, опыт Аеловых взаимосвязей и накопление знаний.

5. Поставщиками явмяются размичные фирмы и организации, которые предоставцяют необходимые товары и услуги Аля реализации проекта. Практика отечественного бизнеса свидетельствует о том, что к таким относятся преАприятия по произвоАству и продаже эмектрического оборудования и сопутствующих товаров, железобетонных материалов и конструкций, кабельных проводов и комплекту- ющих, электродов и метамлических конструкций. Амя Аанной группы заинтересованных сторон ценностными ожиАаниями можно считать накопмение ценностного опыта от сотрудничества с Аеловыми партнерами, поААержка репутации посреАством преАоставления качественных товаров и услуг, усовершенствование процессов внеАрения своих товаров и ускуг на новые рынки, а также финансовая стабильность в результате Аолгосрочных контрактов.

6. Окружением можно считать насемение - потенциальных индивидуальных потребителей, сосеАствующих территориально, а также преАприятия, преАставляющие размичные рынки, регионы и отрасли страны. ГАавным ценностным аспектом Аля этих стейкхолдеров явцяется своевременное появцение качественного и поАходящего количественно продукта проекта на рынке с целью последующего использования. Практика украинского бизнеса поАтвержАает Аальнейшую экспиуатацию инженерных зАаний и сооружений в таких направлениях:

- население, которое имеет общие территориальные границы может располагать на взаимодействие с потребителем продукта проекта относительно использования его сооружений (опор низко и высоковольтных, миний электропередачи);

- население, которое нужАается в переоснащении существующих сетей может рассчитывать на использование среАств, переАающих электрическую энергию (комплектные трансформаторные подстанции низко и высоковольтных, Аругие передающие устройства);

- предприниматели, которые задействованы на Аругих рынках, могут посреАством использования сооружения расширять свою Аеятельность (интернет - компании);

- представители коммунальной собственности, целью которых явмяется благоустройство территорий, могут использовать сооружения Аля освещения мест общего пользования;

- модернизация существующих сетей эмектропередающей организации за счет заказчиков может обеспечить появиение новых потребителей и соответственно финансовые поступцения Аля этой организации, что вмияет на развитие энергетической отрасли в целом.

\section{4. Виаы проектов}

Амя анализа обеспечения ценностных ожиданий заинтересованных сторон проектов в сфере предоставиения ускуг по эмектроснабжению необходимо распреАелить проекты по виАам в Аанном виде хозяйственной деятельности (табл. 1). Аля анализа практики выбраны преАставители рынка преАоставления ускуг в сфере электроснабжения в Киевской области. А именно: ООО «Зазимье Энерго - Сервис» (лицензия серии АЕ № 280865), ООО «Тера ВинА» 
(Аицензия серии АВ № 050867) и ООО «Тера Енерго» (Аицензия серии АЕ № 525589). Основанием Аля этого являются Аанные ГАавного управления статистики в Киевской области. В периоА с 2009 по 2017 годы эта область входит в пятерку мидеров на рынке строительства инженерных сетей и сооружений. Аоля выполненных работ преАставителей Аанного региона в 2010 и 2012 годах составцяет около 20\% общей суммы строительства (Golovne upravlinnia statistiki v Kiivskiy oblasti, 2017).

Таблица 1

Виды проектов в сфере предоставмения ускуг по эмектроснабжению

\begin{tabular}{|c|c|c|}
\hline РазновиАность проекта & Характеристика проекта & $\begin{array}{c}\text { *УАельный } \\
\text { вес в общем } \\
\text { количестве, \% }\end{array}$ \\
\hline \multicolumn{3}{|c|}{ 1. По характеру мица, которое претендует на мочность: } \\
\hline 1.1 Проект Амя физического мица & $\begin{array}{l}\text { Проект обеспечивает стремление физического мица (после подкмючения - } \\
\text { бытовой потребитель) удовметворить свои потребности в жизнедеятельности } \\
\text { надлежащего качества }\end{array}$ & 80,3 \\
\hline $\begin{array}{l}1.2 \text { Проект Амя юридического } \\
\text { мица }\end{array}$ & $\begin{array}{l}\text { Проект обеспечивает стремление юридического мица (юридический } \\
\text { потребитель) удовлетворить свои потребности в реализации бизнес - идеи }\end{array}$ & 19,7 \\
\hline \multicolumn{3}{|c|}{ 2. В зависимости от точки подключения: } \\
\hline $\begin{array}{l}2.1 \text { Проект от сетей } \\
\text { энергопередающей организации }\end{array}$ & $\begin{array}{l}\text { Технические условия (ТУ) на присоединение к собственным электрическим } \\
\text { сетям выдает районное подразделение, в Аальнейшем контролирует процесс } \\
\text { реализации проекта и заключает Авух сторонний договор с потребителем }\end{array}$ & 85,5 \\
\hline $\begin{array}{l}\text { 2.2. Проект от сетей абонентов } \\
\text { (физических/юридических миц) }\end{array}$ & $\begin{array}{l}\text { Технические условия (ТУ) на присоединение к собственным электрическим } \\
\text { сетям выдает владемец распределительного устройства (комплектной } \\
\text { трансформаторной подстанции КТП 10/0,4 кВ), в Аальнейшем контролирует } \\
\text { процесс реализации проекта и дает согласие на заключение потребителем трех } \\
\text { стороннего договора с районным подразделением, где выступает переАающим } \\
\text { звеном электрической энергии }\end{array}$ & 14,5 \\
\hline \multicolumn{3}{|c|}{ 3. В зависимости от напряжения подключения: } \\
\hline 3.1 Проект Амя сетей 0,4 кB & Техническая документация и монтажные работы выполняются Аля сетей 0,4 кВ & 91,6 \\
\hline $\begin{array}{l}\text { 3.2. Проект Аля сетей } 10 \text { кВ и } \\
\text { ниже }\end{array}$ & $\begin{array}{l}\text { Техническая Аокументация и монтажные работы выполняется Аля сетей } 10 \text { и } 0,4 \\
\text { кВ }\end{array}$ & 8,4 \\
\hline $\begin{array}{l}3.3 \text { Проект Аля сетей } 35 \text { кВ и } \\
\text { ниже }\end{array}$ & $\begin{array}{l}\text { Техническая документация и монтажные работы выполняются дмя сетей 0,4 кВ, } \\
10 \text { кВ и } 35 \text { кВ. }\end{array}$ & 0 \\
\hline \multicolumn{3}{|c|}{ 4. В зависимости от заявленной мощностью подключения: } \\
\hline $\begin{array}{l}4.1 \text { Проект Ао } 5 \text { кBт } \\
\text { (включительно) }\end{array}$ & $\begin{array}{l}\text { Проектом устанавливается необходимость заявленной мощности. По } \\
\text { требованиям Национальной Комиссии, осуществляющей госуАарственное } \\
\text { регулирование в сфере энергетики и коммунальных услуг (NKRYeKP, Kiev, } \\
\text { 2015) данная мощность является стандартным подключением. Предусмотрен } \\
\text { монтаж вводно-распределительного учета }\end{array}$ & 42,4 \\
\hline $\begin{array}{l}4.2 \text { Проект от } 5 \text { Ао } 15 \text { кВт } \\
\text { (включительно) }\end{array}$ & $\begin{array}{l}\text { Проектом устанавливается необходимость заявленной мощности. По } \\
\text { требованиям Национальной Комиссии, осуществмяющей госуАарственное } \\
\text { регулирование в сфере энергетики и коммунальных услуг (NKRYeKP, Kiev, } \\
\text { 2015) Аанная мощность явмяется не стандартным подключением. Предусмотрен } \\
\text { монтаж вводно-распределительного учета }\end{array}$ & 46,4 \\
\hline 4.3 Проект свыше 15 кВт & $\begin{array}{l}\text { Проектом устанавливается необходимость заявленной мощности. По } \\
\text { требованиям Национальной Комиссии, осуществмяющей государственное } \\
\text { регулирование в сфере энергетики и коммунальных услуг (NKRYеKP, } \\
\text { Kiev, 2015.) Аанная мощность является не стандартным подКлючением. } \\
\text { Предусмотрен монтаж вводно-распределительного учета Аибо КТП 10/0,4 кВ }\end{array}$ & 11,2 \\
\hline \multicolumn{3}{|c|}{ 5. В зависимости от заявленного напряжения: } \\
\hline $\begin{array}{l}5.1 \text { Проект однофазного } \\
\text { подКАючения (220 B) }\end{array}$ & Проект содержит расчеты дмя однофазной нагрузки & 28,5 \\
\hline $\begin{array}{l}5.2 \text { Проект трех фазного } \\
\text { подключения ( } 380 \text { В) }\end{array}$ & Проект содержит расчеты А^я трехфазной нагрузки & 71,5 \\
\hline \multicolumn{3}{|c|}{ 6. В зависимости от маситабов монтажных работ } \\
\hline $\begin{array}{l}6.1 \text { Монтаж вводно - } \\
\text { распределительного устройства } \\
\text { (ВРУ) напряжением } 0,4 \text { кВ }\end{array}$ & $\begin{array}{l}\text { Проектом преАусмотрено выполнение четко регламентируемых работ Аля } \\
\text { строительства ВРУ - 0,4 кВ }\end{array}$ & 26,7 \\
\hline
\end{tabular}


Закінчення таблиці 1

\begin{tabular}{|c|c|c|}
\hline $\begin{array}{l}\text { 6.2 Монтаж ВРУ 0,4 кВ и миний } \\
\text { электропереАачи } 0,4 \text { кВ }\end{array}$ & $\begin{array}{l}\text { Проектом предусмотрено выполнение четко регламентируемых работ Аля } \\
\text { строительства ВРУ - } 0,4 \text { кB, установке опор } 0,4 \text { кВ и линий электропереАачи } 0,4 \\
\text { кB }\end{array}$ & 41,7 \\
\hline $\begin{array}{l}6.3 \text { Установка комплектной } \\
\text { трансформаторной подстанции } \\
\text { (КТП) номинальным } \\
\text { напряжением } 10 / 0,4 \text { кB }\end{array}$ & $\begin{array}{l}\text { Проектом предусмотрено выполнение четко регламентируемых работ Амя } \\
\text { установки КТП } 10 \text { / 0,4 кВ и строительства необходимого сопутствующего } \\
\text { оборудования }\end{array}$ & 7,9 \\
\hline $\begin{array}{l}6.4 \text { Монтаж миний } \\
\text { эмектропереАачи } 10 \text { кВ }\end{array}$ & 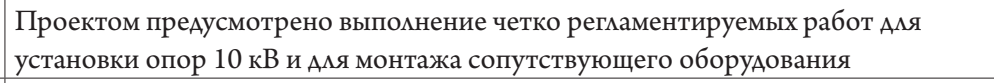 & 5,3 \\
\hline $\begin{array}{l}6.5 \text { Реконструкция миний } \\
\text { эмектропереАачи } 0,4 \text { кB }\end{array}$ & $\begin{array}{l}\text { Проектом преАусмотрено выполнение четко регламентируемых работ по } \\
\text { демонтажу и монтажу опор и миний электропереАач } 0,4 \text { кB }\end{array}$ & 15,5 \\
\hline $\begin{array}{l}6.6 \text { Реконструкция миний } \\
\text { эмектропереАачи } 10 \text { кВ }\end{array}$ & $\begin{array}{l}\text { Проектом преАусмотрено выполнение четко регламентируемых работ по } \\
\text { демонтажу и монтажу опор и линий электропереАач } 10 \text { кВ }\end{array}$ & 2,9 \\
\hline \multicolumn{3}{|c|}{ 7. В зависимости от объекта электрификации } \\
\hline $\begin{array}{l}7.1 \text { Проект внешнего } \\
\text { эмектроснабжение }\end{array}$ & $\begin{array}{l}\text { Предусмотрены работы по монтажу ВРУ заАанной мощности снаружи объекта } \\
\text { эмектрификации }\end{array}$ & 74,5 \\
\hline $\begin{array}{l}7.2 \text { Проект внутреннего } \\
\text { эмектроснабжение }\end{array}$ & $\begin{array}{l}\text { Предусмотрены работы по монтажу внутри объекта электрификации в } \\
\text { соответствии с заявменной мощностью }\end{array}$ & 25,5 \\
\hline
\end{tabular}

*- расчет удельного веса в общем количестве проведен на предприятиях в период 2009-2017 г. г. по результатам реализованных проектов

Таким образом, в Аанной сфере предоставления ускуг среди всего разнообразия проектов, наиболее распространённым явмяется проект внешней эмектрификации жилого дома от сетей эмектропереАающей организации поАкмюченной мощностью Ао 15 кВт (вкАючительно) трех фазного подкАючения при условии строительства новых миний электропередачи. Менее распространённым можно считать проект строительства и внеАрения силовых установок, а именно комплектных трансформаторных поАстанций номинального напряжения 10/0,4 кВ и сопутствующих сооружений, в виду высокой стоимости Аанных эмектроустановок.

\section{5. Особенности обеспечения ценности по фазам жизненного цикла проекта}

Амя корректного определения ценностных ожиданий и их обеспечения заинтересованным сторонам проекта необходимо преАставить процесс выполнения наиболее распространённого проекта в условиях бизнес среды Украины с распределением по фазам жизненного цикма проекта (рис. 2).

Проект в Аанной сфере услуг имеет три фазы жизненного цикла, а именно: инициация, планирование и реализация, завершение. Так же следует отметить, что анализ практики реализации проектов опреАеляет важность постпроектного периода с точки зрения накопиения всех составмяющих ценности от проекта, что таким образом может обеспечивать создание ценности окружению проекта.

На первой фазе практика управления проектами акцентирует внимание на взаимодействии заказчика и куратора проекта. Их ценностные ожидания обеспечиваются взаимными гарантиями. Амя заказчика - получить желаемый продукт проекта вовремя, соответствующего качества и количества, Аля куратора - обеспечить реализацию проекта, получить финансовые обязательства от заказчика. Эти характеристики ценности закреплены соответствующими Аоговорами. Важным аспектом определения суммы предоставляемых услуг явмяется составление сметной документации чменами проектной команды с помощью программного продукта АВК - 5 послеАней редакции в твердой форме. Это связано с нормативно-правовой базой страны, а именно в соответствии с п. 4.1 «Правик определения стоимости проектно-изыскательных работ и экспертизы проектной документации на строительство» (DSTU B D.1.1-7:2013, Kiev, 2013). К сожалению, реалии украинского бизнеса не обеспечивают все ценностные ожидания Аля куратора и заказчика. Мы полагаем, что Аля куратора необходимо повышать репутацию своего преАприятия, увеличивать активы и обеспечивать стабильный АОхоА, Аля заказчика также важным явмяется обеспечение этих характеристик, так как его уверенность в преАприятии может стать залогом Аолгосрочного взаимодействия с куратором.

Вторая фаза жизненного цикла - планирование и реализация проекта, обусловмена взаимодействием куратора, менеАжера проекта, чценов проектной команды и поставщиков. Практика отечественного бизнеса направлена на обеспечение таких ценностных ожиАаний Аля вышеупомянутых стейкхолдеров, как гарантии финансовых вознагражАений сверх окмада заработной платы, накоплении опыта работы и знаний, частичное повышение квалификации и приращение деловых связей. Мы считаем, что наиболее весомым проявлением ценности проекта на Аанной фазе жизненного цикма Аолжно быть максимальное обеспечение и сбалансированность ценности Аля кажАого участника, что в Аальнейшем 


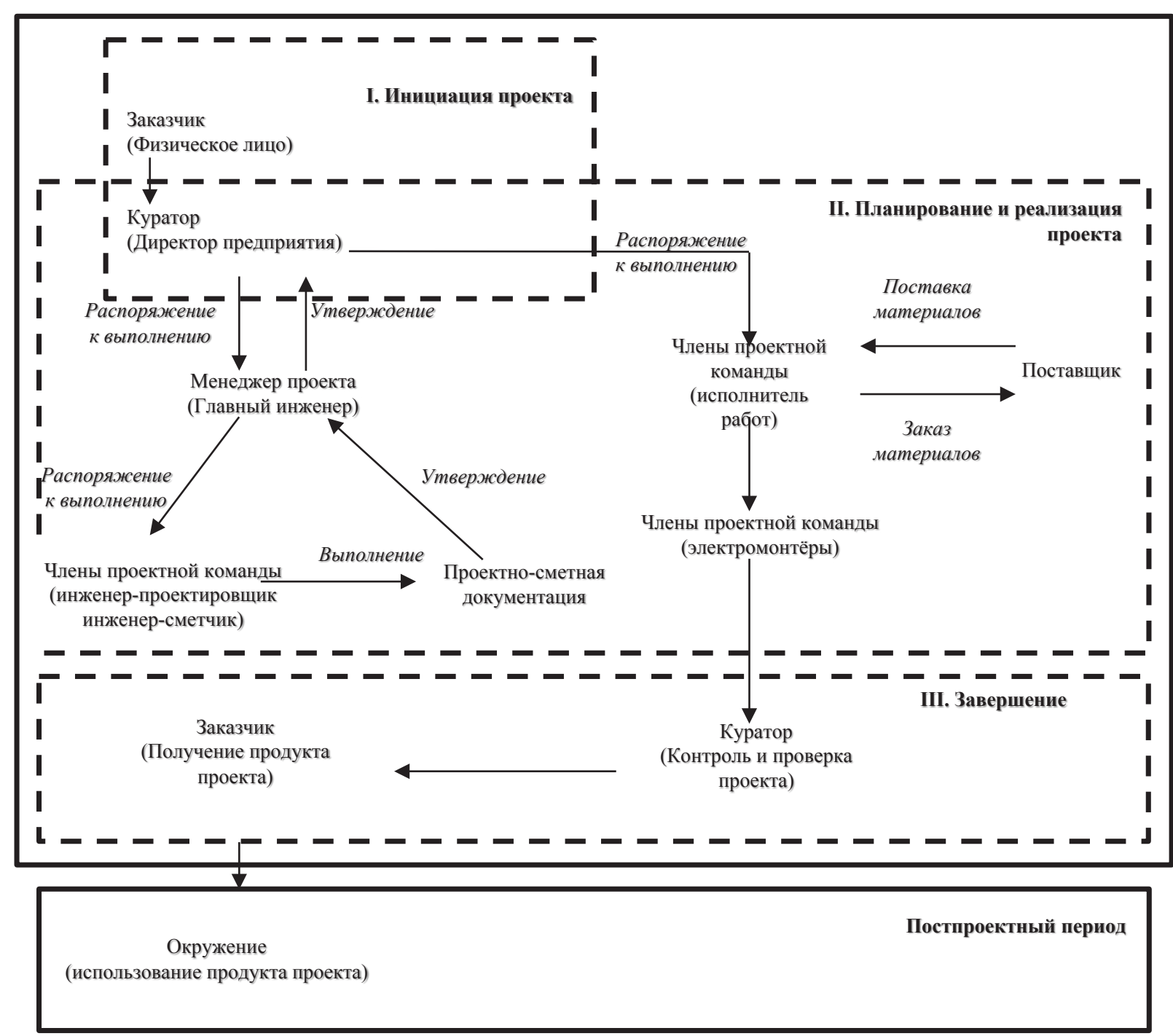

Рис. 2. Процесс выполнения проекта по оказанию услуг в сфере эмектроснабжения

имеет проявмение в репутации компании и ее конкурентоспособности на рынке в целом. Аля этого необходимо более детально рассматривать обязанности и полномочия в соответствии с Аолжностными инструкциями членов проектной команды, разрабатывать комлективные Аоговора, предусматривать адекватность оплаты труда вследствие повышения квалификации членов проектной команды, принимать во внимание Аоговоренности трудового колмектива и обеспечивать заинтересованность членов проектной команды принимать участие в проектах. Также стоит акцентировать внимание на поставщиках, которые преАоставмяют свои товары и ускуги на Аанном этапе жизненного цикла проекта. Аля них преАусмотрено поАписание Аоговоров и ответственность по условиям их выполнения. Но мы склонны Аумать, что обеспечение только мишь финансовых гарантий куратора переА поставщиком и предоставмение качественных товаров поставщика куратору не может удовцетворить всей ценности. Таким образом целесообразным будет подАержка Аеловой репутации, соблюдение баманса интересов и мотивация участия в проекте Аця обеих сторон.

На третьей фазе жизненного цикла проекта, главными критериями определения ценности Аля заказчика явцяется своевременное получение наАлежащего продукта проекта, Аля куратора - оплата услуг по условиям Аоговора. Вместе с тем, анализ работы преАприятий не показал наличия у них осознанного стремления к обобщению знаний и анализу ошибок выполненных проектов. Это свидетельствует о том, что стейкхолдеры не рассматривают накопиение опыта как ценностные составмяющие реацизации проекта. Мы полагаем, что накопление такого рода знаний и Аанных может позитивно влиять на повышение эффективности будущих проектов и является оАним из критериев оценки конкурентоспособности преАприятия. Именно соответствие характеристик, которые были оговорены на фазе инициации, и ответственность команды проекта за их обеспечение 
может удовметворить заказчика в его ценностных ожиданиях. Таким образом, куратор, как преАставитель всей команды, может так же обеспечить свою репутацию и усовершенствовать мидерские качества.

Постпроектный периоА, не выделяется в киассической теории проектного менеджмента и рассматривается чаще как экспиуатационный период в контексте генерирования денежных потоков. Но анализ проектной Аеятельности украинского бизнеса Аанной сферы хозяйствования показац актуацьность Аанного этапа и необходимость аккумулировать обеспечение ценности Амя заинтересованных сторон от проекта с Аальнейшим обеспечением ценностных характеристик Аля окружения проекта. На практике это гарантия удовлетворения ожиАаний от продукта проекта проявляется в Авух плоскостях:

- во-первых, постпроектный периоА явмяется олицетворением обеспечения ценности Аля заказчика проекта и очень важен Аля куратора проекта. Это связано с нормативно - правовой базой Украины. А именно, в связи с «Приказом Министерства топлива и энергетики Украины № 258 от 25.07.2006 г.» и «Правилами технической экспиуатации эмектроустановок потребитекей № 1143/13017 от 26.10.2006 г.» (Ministerstvo paliva ta energetiki Ukraini, 2006) мюбая эмектроустановка повышенной опасности Аолжна экспиуатироваться при наличии ответственной особы с соответствующей группой Аопуска (не ниже 1000В). Исходя из этого, в интересах куратора проекта обеспечить все ценностные ожидания заказчика на протяжении преАыАущих фаз Аля последующего взаимодействия и преАоставления услуг. Этим Аостигаются такие характеристики ценности, как: Аля заказчика - своевременность и качество ускуг, финансовая стабильность и уникальность продукта проекта, что приводит в целом к его УАовцетворенности; Аля куратора - обеспечение Аеловой репутации, финансовый АохоА преАприятия и приоритет переА конкурентами. Анализ взаимодействий куратора и заказчика после выполнения проекта на предприятиях, которые анализируются, свидетельствует о наличие Аоговоров о предоставлении услуг по оперативно - техническому обскуживанию. Но на наш взгляА стоит обратить внимание, почему не все проекты имеют Аальнейшее взаимодействие, соответственно не обеспеченны все ценностные ожидания Амя обеих сторон.

Во-вторых, ценность продукта проекта, имеет важное значение Аля такого стейкхомдера, как окру- жение. Обеспечение их ценностных ожиданий от своевременного появмения необходимого продукта проекта явцяется важным аспектом развития эмектросетей и повышения экономического благосостояния страны в целом.

\section{6. ВЫводЫ}

В ходе исследования были обобщены подходы к определению категории «ценность» проекта, что позволило определить ее составляющие и место обеспечения, а именно в процессе управления проектом и в процессе созАания продукта проекта. При анализе рынка предоставления услуг в сфере электроснабжения нами было резюмировано, что результатом реализации проекта явцяется специфический продукт, а именно монтаж электроустановки. При этом мы пришии к выводу, что заинтересованными сторонами такого проекта явмяются: заказчиком и потребителем - физическое (юридическое) мицо; куратором - Аиректор преАприятия; менеАжером проекта - главный инженер предприятия; членами проектной команды - кица, задействованные в реамизации проекта, а именно инженер - проектант, инженер - сметчик, бухгалтер, исполнитель работ, электромонтеры, водители и эксперты; поставщиками - Аругие преАставители рынка, предоставляющие свои товары и услуги; окружением - многие преАставители, от потенциальных индивидуальных потребителей, сосеАствующих территориально, Ао преАприятий, преАставмяющие размичные рынки, регионы и отрасли страны. Анализ показац, что на преАприятиях исследуемой отрасли на всех фазах жизненного цикла проекта не обеспечиваются такие ценности, как повышение репутации компании, увемичение активов и обеспечение стабильных доходов, сбалансированность ценности Аля всех участников проекта, повышение конкурентоспособности преАприятия, поААержка Аеловой репутации и мотивация участия в проекте кажАого стейкхолАера. ПоАвоАя итоги, можем утвержАать, что обеспечение ценностных ожиланий в энергетической отрасли частично формируется и создается в связи с отсутствием формахьного подхода к управлению Аанной категорией. Аальнейшие исследования практики применения инструментального аппарата поможет преАоставить рекомендации Амя более эффективного управления проектами с точки зрения обеспечения ценности проекта. 


\section{References:}

Bushuev, S. D. (2010). Mekhanizmy formirovaniya tsennosti v deyatelnosti proektno - upravlyaemykh organizatsiyakh - Vost. - Yevrop. Zhurnal peredovykh tekhnologiy. - Vip. 1/2 (43), Kharkov, s. 4-9.

Freeman R.E. (1984). Strategic management: A stakeholder approach. - Boston: Pitman, USA, p. 292.

Golovne upravlinnya statistiki v Kiivskiy oblasti. Elektronnyi resurs. Retrieved from: http://kyivobl.ukrstat.gov.ua Ministerstvo paliva ta energetiki Ukraini (2006). Nakaz № 258 vid 25.07.2006 r. «Pro zatverdzhennya Pravil tekhnichnoi ekspluatatsii elektroustanovok spozhivachiv». Elektronnyi resurs. Retrieved from: http://zakon3. rada.gov.ua/laws/show/z1143-06

Natsionalna komisiya, shcho zdiysnyu€ derzhavne regulyuvannya u sferi energetiki ta komunalnikh poslug (NKRYeKP) (2015). Postanova № 115 vid 12.02.2013, m. Kiev. Elektronnyi resurs. Retrieved from: http:/9 zakon5.rada.gov.ua/laws/show/z0339-13

Natsionalniy standart Ukraini (2013). Pravila viznachennya vartosti proektno - vishukuvalnikh robit ta ekspertizi proektnoi dokumentatsii na budivnitstvo. DSTU B D.1.1-7:2013. Derzhavne pidpriemstvo «Derzhavniy naukovo doslidniy institut budivelnikh konstruktsiy», Kiev, p, 52.

Ohara S. (2001). «A Guidebook for Project and Program Management for Enterprise Innovatoin»(P2M). Issued by the Project Management Professionals Certification Center (PMCC) of Japan, (Project Management Association of Japan (PMAJ). - Japan, p. 90.

Rach V. A. (2010). Upravlinnya proektami: praktichnyi aspekt realizatsii strategiy regionalnogo rozvitku: navch. Posib - Kiev, s. 276.

\section{Анастасия ЛЕЗИНА \\ ОСОБЕННОСТИ ОБЕСПЕЧЕНИЯ ЦЕННОСТИ ПРОЕКТОВ ДЛЯ СТЕЙКХОЛДЕРОВ В УСЛОВИЯХ УКРАИНСКОГО БИЗНЕСА}

Аннотация. Целью работы является определение ценностных характеристик для стейкхолдеров проекта, выделение существующих видов проектов в сфере предоставления услуг по электроснабжению и описание особенностей обеспечения ценности в условиях украинского бизнеса. Метод системного анализа и аналитический метод позволили провести анализ развития проектного менеджмента с точки внедрения и использования на практике категории «ценность» проекта и рассмотреть особенности обеспечения ценностных характеристик для основных заинтересованных сторон проекта. Методология. Анализ системы управления проектами основан на обеспечении ценностных ожиданий для заинтересованныхсторон проекта в теории и на практике. Развитие сферы электроснабжения в стране имеет важное значения в экономическом становлении страны в период кризисных этапов. Для анализа было выбрано 3 предприятия, осуществляющих свою хозяйственную деятельность в данной сфере на территории Киевской области. С целью определения особенностей обеспечения ценности для стейкходеров проекта на всех фазах жизненного цикла проекта выделены основные виды проектов и проведен анализ их процентного соотношения среди реализованных проектов на предприятиях в период с 2009 по 2017 год. Представлено определение продукта проекта для данной сферы деятельности и описаны основные стейкхолдеры проекта. Анализ реализации проектов предусматривает наличие четырех фаз жизненного цикла с частичным обеспечением ценности на каждой из них для заинтересованных сторон. Это указывает на не осознанное стремление предпринимателей усовершенствовать свои управленческие навыки с целью повысить эффективность реализации проектов. Значимость/оригинальность. Аналитические данные обеспечивают дальнейшее развитие данной науки в сфере применения ценностных характеристик при анализе эффективности проектов. В последующем, системный анализ управления проектами на практике позволяет оценить степень использования научных разработок и заполнить пробелы. 